\title{
Correction to: Freezing Technology: Control of Freezing, Thawing, and Ice Nucleation
}

\section{Peter Kilbride and Julie Meneghel}

\section{Correction to:}

Chapter 6 in: Willem F. Wolkers and Harriëtte Oldenhof (eds.), Cryopreservation and Freeze-Drying Protocols, Methods in Molecular Biology, vol. 2180, https://doi.org/10.1007/978-1-0716-0783-1_6

This chapter was previously published non-open access and has now been changed to open access under a CC BY 4.0 license under the terms of the Creative Commons Attribution 4.0 International License (http://creativecommons.org/licenses/by/4.0/) and the copyright holder has been updated to "The Author(s)". The book has also been updated with this change.

The updated online version of the chapter can be found at https://doi.org/10.1007/978-1-0716-0783-1_6 